\title{
Análise sociossemiótica dos modos de vestir na velhice
}

Sociosemiotic analysis of the ways of dressing in the elderly 


\section{Rachel Ferreira Loiola}

ORCID: https://orcid.org/0000-0003-3686-8840

[resumo] 0 ato de se vestir vai muito além da função estética, do adornar-se. São arranjos que envolvem escolhas de tecidos, cores, acessórios, movimentos permitidos e sensações a partir do toque das roupas. No vestir estão imbricados aspectos afetivos, históricos e sociais que, se bem analisados, revelam características essenciais da expressão e da identidade do sujeito e sua interação com as roupas. A sociedade, influenciada pelos ideais de beleza pela busca da eterna juventude, percebe o envelhecimento de forma disfórica. A moda, nessa perspectiva, aparece para cobrir o corpo que envelhece e que deve ser discreto em relação aos mais jovens. Seria esse o caminho viável a uma escolha ética ligada a uma estética da existência? Esta pesquisa tem o objetivo de compreender os sentidos da moda no envelhecimento considerando as interações entre os idosos e suas roupas como práticas e modos de viver. A análise foi realizada a partir de uma abordagem sociossemiótica desenvolvida por Greimas, pelos desdobramentos dinâmicos dos regimes de interação encaminhados por Eric Landowski e pelos simulacros de aparência propostos por Ana Cláudia de Oliveira.

[palavras-chave] Envelhecimento. Moda. Regimes de interação. Sociossemiótica. Aparência.

[abstract] The act of dressing goes far beyond the aesthetic function, of adorning oneself. These are arrangements that involve choices of fabrics, colors, accessories, allowed movements and sensations from the touch of clothes. In dressing, affective, historical and social aspects are interwoven which, if well analyzed, reveal essential characteristics of the expression and identity of the subject and their interaction with clothes. Society, influenced by the ideals of beauty and the search for eternal youth, perceives aging in a dysphoric way. Fashion, in this perspective, appears to cover the aging body and that must be discreet in relation to the younger ones. Is this the only viable path to an ethical choice linked to an aesthetics of existence? This research aims to understand the meanings of fashion in aging considering the interactions between the elderly and their clothes as practices and ways of living. The analysis considered the interactions between the elderly and their clothes, being carried out from a socio-semiotic approach developed by Greimas, by the dynamic developments of the interaction regimes developed by Eric Landowski and by the appearance simulations proposed by Ana Cláudia de Oliveira.

[keywords] Elderly. Fashion. Interaction Regimes. Sociosemiotics. Appearance.

Recebido em: 03-08-2020

Aprovado em: 13-10-2020

\footnotetext{
${ }^{1}$ Fonoaudióloga, Doutora em Análise do Discurso, Linguística pela Universidade Federal de Minas Gerais (UFMG). Pós-doutoranda e pesquisadora do Centro de Pesquisa Sociossemiótica na PUC-SP. E-mail: Rachel. loiola@me.com. Lattes: https://wwws.cnpq.br/cvlattesweb/PKG_MENU.menu?f_cod=D90AD86A068D7D25CCB16E985F9382AB\#.
} 


\section{Introdução}

"O que a mocidade deseja, a velhice o tem em abundância."

(Goethe)

Vestir-se é um ato que envolve escolhas, sensações, composições e uma gramática própria da moda. Os arranjos consideram cores, tecidos, acessórios que indicarão um modo de presença específico, manifestando a identidade e a subjetividade de quem veste. A seleção do que vestir conjuga assim aspectos afetivos, históricos e sociais refletindo maneiras e estilos de viver.

Com os idosos, que muitas vezes são colocados à margem do universo da moda na publicidade, nos desfiles e até nas confecções das peças de roupas, as produções de sentido do vestir não são diferentes. Luiz Fernando Veríssimo (2018) narra, com maestria, na crônica intitulada Meias uma lista que é feita no Natal para presentear os familiares, sendo um dos critérios da relação idade. 0 personagem da crônica, ao receber apenas meias de lã, comenta: "Você entra na lista das meias quando eles decidem que você não precisa, não merece ou não se interessa por mais nada. Ou não tem mais idade para outra coisa". Justifica ainda sobre o material das meias recebidas: "Se presume que não têm outra ambição ou gosto na vida senão manter os pés quentes. Meias de outro material ainda deixam subentendida a possibilidade, mesmo remota, de uma recuperação. A medicina hoje faz milagres, você ainda pode voltar para a lista da loção. Até mesmo da gravata. Mas da lista das meias de lã ninguém sai..." (VERÍSSIMO, 2018, p. 73).

Meias de lã, roupas acinzentadas, discretas e sóbrias foram peças destinadas aos idosos considerados um público pouco produtivo, sem ambições e restrito ao ambiente doméstico. Diante das transformações da sociedade brasileira ao longo dos anos, especialmente as relacionadas às taxas de natalidade e expectativa de vida, questiona-se: os idosos de hoje são os mesmos de outrora? Que sentidos podem ser percebidos a partir da interação deles com suas roupas?

\section{Desenvolvimento}

\section{Envelhecimento}

A necessidade de estudos sobre os idosos não se justifica somente pelo seu aumento populacional, como cita Guita Grin Debert (1998), mas representa uma oportunidade de problema que ganha expressão e legitimidade no campo das preocupações sociais contemporâneas. 0 Brasil é um dos países com o mais rápido processo de envelhecimento ao redor do mundo. Por se tratar da quinta maior população global, o envelhecer dos brasileiros tem repercussões que transcendem as fronteiras do país. Essa mudança demográfica traz oportunidades e desafios ainda não inteiramente compreendidos.

As novas projeções para a população brasileira demonstram que, de 233,2 milhões de pessoas em 2018, passará estimadamente para 228,2 milhões de habitantes em 2047 
(IBGE, 2019). Portanto, está a caminho da transição do crescimento para o decrescimento demográfico. Outra alteração confirmada é a da estrutura etária. Durante mais de 500 anos, o Brasil teve uma estrutura etária rejuvenescida, mas que mudará no decorrer do século XXI.

De acordo com o IBGE (2019), o Índice de Envelhecimento (IE) destaca que o número de jovens vem caindo para 44,5 milhões e o de idosos subindo para 28 milhões, ficando o IE em 63 idosos para cada 100 jovens. Em 2031, o número de idosos vai ultrapassar o de jovens quando haverá 42,3 milhões de jovens ( 0 -14 anos) e 43,3 milhões de idosos ( 60 anos e mais), chegando a 102,3 idosos para cada 100 jovens. Esse envelhecimento populacional continuará sua marcha inexorável ao longo do século XXI, indicando projeções para 2055 do dobro de pessoas mais velhas em relação às mais novas. Com toda essa revolução, não há como não se importar com o novo grupo etário que comandará em números o nosso país!

A experiência de envelhecimento surge a partir de uma confluência de manifestações que são tanto exteriores quanto interiores ao corpo físico. Ou seja, a autopercepção da velhice passa tanto pelas questões do corpo orgânico, como aparência, energia e saúde, quanto pela idade interativa, que se caracteriza pela idade que o outro enxerga no sujeito (MINICHIELLO, BROWNE e KENDIG, 2000). As roupas que vestem os corpos dos idosos destacam-se como elementos importantes para as questões de aparência, como cita Ana Cláudia de Oliveira:

Os corpos vestidos são então construções do social e analisá-los em suas manifestações é entender o processo de expressão de um eu, o do criador, do destinador na sua grande gama de sujeitos possíveis - que tanto pode ser a marca, ou a cadeia midiática que a faz circular, ou o usuário, no seu estar vestido para estrelar nas suas cenas performáticas, igualmente uma amplidão que configura a sociedade em que essa manifestação se dá como o seu próprio sujeito concretizado em pele (transformações do e no corpo) ou tecido (novas propostas para as roupas e moda). (OLIVEIRA, 2009, p. 42)

Antes de adentramos no universo do vestir do idoso, faz-se relevante investigar quem é o sujeito que envelhece nos dias de hoje.

\section{Idosos: conceitos e definições}

Para compreender as percepções cristalizadas do envelhecimento e seus efeitos como produção de sentido foram analisadas as terminologias descritas nos dicionários da língua portuguesa. Os significados associados ao envelhecer revelaram sentidos disfóricos, assim como seus sinônimos, direcionando os conceitos para um fim, um acabar, um terminar, um apagar-se. A polaridade negativa ficou ainda mais evidente quando foram pesquisados os antônimos, que se revelaram como palavras de polaridade positiva: revigorar, rejuvenescer, renovar, reflorescer, reflorir, reamanhecer, remoçar, reverdecer.

Atualmente, percebe-se uma proliferação das nominações utilizadas para se referir à velhice, como terceira idade, melhor idade, adulto maduro, idoso, velho, meia-idade, maturidade, idade maior e idade madura. Em termos constitucionais, houve também uma busca 
pela terminologia mais adequada para se aludir a essa população: velhos, anciãos, terceira idade, melhor idade, pessoas idosas e idosos. Por fim, o Estatuto do Idoso escolheu as palavras "idosos" ou "pessoas idosas" para nomear essa população (ESTATUTO DO IDOSO, 2003).

Não há, dessa forma, descrição ou percepção dessa fase como uma etapa da vida como qualquer outra, muito menos como uma época positiva, associada à possibilidade do alcance de uma longa vida ou de sabedoria. Entretanto, nada deveria ser mais esperado e previsto do que a velhice, compreendida inúmeras vezes como imprevista e decadente!

Faz-se necessário um processo de reeducação de toda a sociedade para superação de ideias preconceituosas em torno da velhice, envolvendo aceitação e compreensão da realidade das etapas da existência humana. Como descreve Simone de Beauvoir em seu livro A velhice:

Paremos de trapacear; o sentido de nossa vida está em questão no futuro que nos espera; não sabemos quem somos, se ignorarmos quem seremos: aquele velho, aquela velha, reconheçamo-nos neles. Isso é necessário, se quisermos assumir em sua totalidade, nossa condição humana. (BEAUVOIR, 2018, p. 11)

Compreendido dessa forma, o envelhecer pode ser visto como escolha ética ligada a uma estética da existência e de uma grande saúde (dimensão da vida que não exclui a morte e a doença). Essa estética para a velhice, de acordo com Silvana Maria Corrêa Tótora (2016), envolve a compreensão da velhice nas suas múltiplas singularidades, como resistência a uma representação prolongada e oponível aos padrões majoritários de jovem (= saúde) versus velho (= doença). Entretanto, a nossa sociedade ainda apresenta dificuldades para compreender o envelhecimento como fortalecimento de uma existência, sendo influenciada em larga medida pela mídia e suas noções de beleza e padronização corporal.

\section{O corpo, a mídia e a beleza na velhice}

Na cultura japonesa, tem-se o hábito do uso do vermelho nas roupas de comemoração dos 60 anos de idade, por ser uma cor associada aos deuses. A utilização do vermelho inaugura uma nova fase da vida, relacionada ao divino. Quem tem permissão para usar o vermelho tem permissão para tudo! Percebe-se, assim, um sentimento de alegria, euforia e valorização da cultura japonesa ao se comemorar os 60 anos e entrar na chamada terceira idade. Na cultura brasileira, não há esse ritual. Teriam os nossos idosos motivos para celebrar o envelhecimento? Qual seria a nova roupagem do público maduro brasileiro?

Inicialmente, vale nos determos em um relevante aspecto sobre o vestir, uma vez que envolve escolhas a respeito de cobrir ou esconder um importante objeto de valor do mundo contemporâneo: o corpo. Ele pode ser considerado como um objeto na interação entre corpo e roupa, entre corpo e identidade, pois representa um discurso que traz consigo marcas de uma cultura que se manifesta por meio da competência de um fazer capaz não apenas de veicular, mas, sobretudo, de garantir a apreensão da significação. No corpo estão registradas as características que definem cada indivíduo, demonstrando sua ontogenia cultural. Ele representa um dos canais de materialização do pensamento, do perceber e do sentir circundante. É o responsável por conectar o ser com o mundo 
habitado, real ou construído. Não é mero suporte ou veículo da roupa, mas um dos seus constituintes. Assim, corpo e moda apresentam-se como textos acoplados, com organização linguageira própria, como cita Kathia Castilho:

O corpo sempre se oferece como suporte gerador de significação, articulador de um discurso que permite a ação da plasticidade da decoração corpórea nas situações de interação, presentificação e representação pelo contrato que determina valores positivos e negativos que podem ser, em linhas gerais, polêmicos ou contratual, implícito ou explícito. (CASTILHO, 2004, p. 139)

O Brasil é um país que possui como importantes capitais de valor a beleza e a juventude, sendo considerado o segundo país que mais realiza cirurgias plásticas do mundo, sobretudo pelas mulheres. As principais motivações das intervenções, de acordo com Mirian Goldenberg (2010), são: atenuação dos efeitos do envelhecimento, correção de defeitos físicos e a busca pelo corpo perfeito. A procura incessante pelo corpo ideal é influenciada fortemente pela mídia que elege sempre formas belas, jovens e desejadas para veicular seus produtos.

As campanhas publicitárias voltadas para os idosos (do gênero feminino ou masculino) sempre os colocam como assexuados, doentes, altamente dependentes e, muitas vezes, solitários, focando em valores como saúde, cuidados e, principalmente, em como retardar cada vez mais esse envelhecimento. A mídia é, assim, grande incentivadora de uma visão distorcida sobre o envelhecer, manipulando o sentir da sociedade frente ao idoso e reforçando ideais e padrões preestabelecidos. Os simulacros das imagens construídas pela indústria de cosméticos ou pela mídia coisificam a beleza, simplificando-a, tirando o real sentido do belo. Desse modo, a estética da mídia desumaniza, corrompe o corpo e a essência torna-se produto (MORENO, 2008). As propagandas de cremes faciais, por exemplo, anunciam a promessa de rejuvenescimento com os cosméticos anti-idade, ou seja, contra a idade. 0 belo está na pele lisa, esticada, e o feio são as rugas, as linhas de expressão e as marcas da vida. Se os cremes, vitaminas e compostos fossem vendidos e anunciados aos seus consumidores para garantir um envelhecimento da pele ou do corpo com mais qualidade, em vez de impedir esse envelhecer, os efeitos de sentidos seriam diferentes. A paralisação das mudanças da vida por meio de uma beleza plastificada transforma a essência de uma vida vivida em produto, destituindo os sentimentos genuínos e sensíveis a favor do belo.

Se a nossa imagem é apenas um reflexo daquilo que somos, então a beleza na velhice pode se revelar com mais intensidade do que se mostraria na juventude. Compreendendo dessa forma, a beleza provocaria a libertação e não a escravidão pela busca incessante de uma juventude ilusória. Envelhecemos para sermos agraciados de meios necessários para entender a nossa existência. Sem percorrer a estrada, é impossível deslumbrar lembranças, porque são elas que nos dão condição plena de podermos tecer a trama do sentido da vida. Somos um pouco de tudo e de todos, e, ao longo do tempo, potencializamos cada vez mais os nossos propósitos. Portanto, envelhecer pressupõe inspiração para a beleza!

Fernanda Ramos de Albuquerque Lima (2020), em estudos recentes, descreve que a publicidade, especialmente a de cosméticos, vem passando por algumas transformações, 
buscando tornar representativa a população feminina com a divulgação de pessoas mais reais, incluindo as mulheres negras, obesas e idosas. As propagandas, segundo a autora, vêm adotando outras estratégias de manipulação, pois estão percebendo o perfil crítico das novas consumidoras que se posicionam com um discurso mais inclusivo e positivo. Essa perspectiva publicitária atual, embora tenha interesses evidentes voltados à venda de seus produtos, pode representar um caminho inicial para uma outra visão do idoso no mundo midiático.

Com as reflexões sobre corpo, influências midiáticas e beleza, passemos para os regimes de interação, abordagem utilizada para análise do vestir no envelhecimento.

\section{Os regimes de interação}

Para Eric Landowski (2014), a proposta de uma análise semiótica é observar, comparar e interpretar os dispositivos simbólicos por meio dos quais a realidade chega a significar para os sujeitos. Essa investigação consiste na busca pela significação e pelos sentidos de vida. Para Algirdas Julius Greimas (2017), a experiência do sentido pode ser vista como uma salvação, uma liberação ou uma escapatória. Assim, as escolhas sobre os nossos modos de viver, de interagir com as pessoas e estar no mundo fazem parte de um equilíbrio entre identidade e diferença, euforia e disforia, continuidade e descontinuidade, possibilidade e necessidade que revelam nossas construções de sentidos existenciais.

Landowski (2014) propõe um sistema dinâmico com deslizamentos entre os regimes de interação, oriundo da teoria narrativa de Greimas com ampla aplicabilidade nas diversas relações possíveis. Sua proposta, de acordo com Paolo Demuru (2019), apresenta duas importantes contribuições: valor existencial, percebido a partir dos estilos de vida possíveis que orientam a experiência e o comportamento dos sujeitos; base para teorizar a dinâmica dos processos socioculturais e comunicacionais, ou seja, as formas como as sociedades, as culturas e os processos comunicacionais se estabelecem geográfica, histórica e temporalmente.

Da semiótica narrativa tradicional são reconhecidas duas formas de interação: uma regular e de ações programadas sobre as coisas e outra carregada de intencionalidade, sendo de caráter manipulatório. Landowski acrescenta, além dos dois regimes de interação citados, sistemas fundados na sensibilidade dos interactantes e outro pautado na aleatoriedade.

Os quatro regimes de interação não são fixos, nem estáveis, mas transitam entre si de forma fluida e dinâmica, variando de acordo com o estilo e a fase da vida do interactante, pelos quais um sujeito se relaciona e transita ao longo da sua história. Essas articulações fornecem, em seu conjunto, uma possível semiótica da experiência (LANDOWSKI, 2017), capaz de problematizar a dinâmica dos processos socioculturais e comunicacionais.

\section{O vestir na velhice e os regimes de interação}

O vestir é um arranjo complexo que envolve a escolha de tecidos, cores, caimento, estilo, acessórios e motivações. Esse conjunto de preferências tem uma gramática própria determinada pelo gosto, pelas experiências e pelas vivências de quem se veste, como cita Greimas: 
vestir-se é coisa séria e toda inteligência sintagmática é empregada nesse ato: eis aí uma sequência de vida "vivida" como uma sucessão ininterrupta de escolhas e que conduz pouco a pouco à construção de um objeto de valor. (GREIMAS, 2017 p. 83)

Analisar um corpo vestido envolve lidar com os simulacros da aparência, que é um dos modos mais complexos de construção da visibilidade de um sujeito (OLIVEIRA, 2007). Dessa forma, considera-se a primeira roupa do sujeito analisado a própria pele. No caso do público investigado nesta pesquisa, a pele é cheia de marcas, cicatrizes, rugosidades e cores variadas. Cada uma delas revela experiência, histórias de vida e sentimentos inscritos. A roupa propriamente veste um corpo, que não é vazio, mas um cenário da história viva de cada um que carrega sentidos construídos ao longo da vida. Corpo e roupa operam trocas recursivas que podem ora um se destacar sobre o outro, ora se acoplar em uma fusão harmônica.

De acordo com Oliveira (2007), há quatro possibilidades desse encontro da roupa com o corpo:

a) vestir-se para si, na qual roupa e corpo encontram-se integrados em um regime de união;

b) vestir-se pela roupa, na qual a roupa é que mostra o corpo, destacando-se sobre este, em um regime de junção;

c) vestir-se com fins práticos, voltado para a funcionalidade sendo a moda escolhida pelo seu fim, em um regime de reunião entre corpo e roupa sem destaque de um sobre o outro;

d) vestir-se com fins simbólicos, no qual a roupa e o corpo juntos operam como status social em um regime de junção.

Usando o esquema dinâmico dos regimes de sentido proposto por Landowski (2014), apresento as seguintes possibilidades para compreensão do vestir na velhice

a) Programação: 0 nosso corpo é programado para envelhecer desde que nascemos, sendo um processo inerente à vida, do mesmo modo que o nascimento, o crescimento, a reprodução e a morte. Não é um acidente mecânico, mas cada um traz em si o envelhecer, como um fruto traz a sua semente. Percebidos em uma perspectiva biológica, temos no envelhecer algo como o inevitável, o previsível que segue um programa narrativo preestabelecido pelo sistema fisiológico do corpo humano. Vale ressaltar que, embora inevitável, o envelhecer pode ser sentido e percebido de formas diferentes dada a subjetividade, os modos de viver de cada um e outros fatores como saúde, hereditariedade, meio, emoções, hábitos passados.

Sobre o vestir na velhice, o que é programado e esperado em nossa sociedade, embora tenhamos sinais de uma mudança sutil e progressiva, é a regularidade de um dever ser mais comportado nessa fase, um dever ser menos audacioso e aventureiro nas cores e nas modelagens das roupas. Ainda há os que associam os idosos àqueles que ficam em casa bordando, cozinhando ou apenas cuidando dos netos, o que os levam a usarem roupas confortáveis, para ficar em casa e sem grandes novidades. Denise Pollini (2014) descreve que a formalidade nas roupas ficou relacionada a situações específicas ou a um mundo que remete ao passado. 0 formal passou, então, a adquirir conotação de antigo. 0 vestir-se, na programação, tem fins práticos e funcionais, estando o corpo e a roupa reunidos sem o destaque de um sobre o outro. Assim, junto da invisibilidade pelas cores apagadas e poucos evidentes, 
destaca-se o estilo mais tradicional e clássico tendendo ao conservadorismo na programação. Corpo e pele aparentes a partir de roupas mais ousadas e sexies são criticadas, pois fazem parte do grupo de roupas que não devem ser vestidas. Essas regras justificam-se pelos idosos serem percebidos, muitas vezes, como assexuados, sendo a função da sedução do corpo e da roupa reservada ao público jovem. Retomo aqui o conto de Luiz Fernando Veríssimo sobre os presentes recebidos de Natal: meias de lã! Esse presente revela ao idoso o papel de ficar em casa, assumir o fim de sua participação na sociedade e, também, na moda.

b) Manipulação: A interação do indivíduo com o próprio envelhecimento poderá ser uma afirmação ou uma negação. 0 envelhecer pode ser acolhido de forma positiva por quem chega à maturidade com objetivação e adaptações intencionais dos espaços, rotinas e práticas do viver diante das novas e prováveis configurações físicas. Uma rotina com carga de trabalho menor, a inclusão de atividades prazerosas durante a semana, a mudança para um espaço com menos escadas, cuidados com alimentação e atividades físicas regulares, por exemplo, podem ser estratégias para uma velhice bem desfrutada. 0 idoso aqui deve ser visto como dotado de competência modal para adaptar-se. Criar estratégias intencionais para uma vida mais segura e com qualidade é, portanto, uma forma de aceitação das condições esperadas no envelhecer.

Por outro lado, negar o envelhecimento, não aceitar ajuda ou buscar disfarçar a velhice por meio de técnicas de rejuvenescimento são manipulações de quem quer estender a juventude e, de certa forma, não experimentar o que a idade oferece. Voltamos ao esquema apresentado inicialmente no qual a juventude é eufórica, associada com as cores, a vitalidade e a alegria, e o envelhecimento, disfórico, decadente e sem graça.

Quanto ao vestir, o idoso poderá adotar estratégias de manipulação escolhendo para o seu repertório roupas que o façam parecer mais jovem e disfarcem (ou neguem) a idade que possui. Essas estratégias podem estar associadas ao uso de cores mais vibrantes, estampas, tecidos, peças com cortes ajustados, uso de maquiagens que cubram ou atenuem suas linhas de expressão e acessórios variados. 0 que definirá se é um tipo de manipulação ou ajustamento (regime apresentado a seguir) é a relação do idoso com o próprio envelhecer.

Comparando o vestir entre os idosos brasileiros com os alemães, pode-se constatar que a roupa no país europeu também participa de um processo de envelhecimento da aparência. No Brasil, ao contrário, a tendência é vestir-se como jovem até bem tarde. É a filha que empresta suas roupas para a mãe (CARADEC, 2011). Em uma sociedade tão pautada para uma estética jovem, a tipificação do vestir ganha até uma nova categoria: a adultescência. Nesse caso, as roupas ficam subordinadas ao corpo, revelando uma narrativa do próprio corpo como vestimenta em si.

Na mídia e nas redes sociais, os atores e atrizes que não aparentam a idade que têm, e desfilam nas passarelas da vida com roupas joviais, são tidos como exemplos de um envelhecer saudável. Na outra ponta do espectro, o uso de roupas largas e confortáveis ou de um vestir sem um querer jovial (assim como o assumir dos cabelos brancos, especialmente pelas mulheres) é associado ao descaso, descuido e desleixo quanto ao envelhecer. Estamos tão acostumados com as atitudes manipuladoras do ciclo da eterna juventude que deter o processo de envelhecimento por meio do vestir tornou-se obrigatório, e não aliar-se a isso soa como preguiça e descaso. 
c) Acidente: Desfrutar de uma velhice saudável é o que todos que envelhecem desejam. Entretanto, os idosos podem ser acometidos por doenças que os desestabilizam e comprometem negativamente o sentir da maturidade. Essas enfermidades podem ser consideradas aleatórias e acidentais, pois não há uma previsão ou expectativa certa para que apareçam, embora haja uma maior probabilidade de surgirem com o passar dos anos. Além disso, a adoção de cuidados ao longo da vida pode ser uma prevenção para o viver de um envelhecimento saudável. Ainda assim, é possível ocorrerem quedas, acidentes vasculares encefálicos, aparecimento de câncer, entre outras distúrbios que farão com que o idoso crie estratégias para lidar com as doenças (tratamento ou reabilitação) e se ajuste às novas condições. Os modos de viver ao longo da vida serão fundamentais para o idoso lidar com esse inesperado.

Para uma sociedade que sente o envelhecimento de forma disfórica, e com finitude de oportunidades, novos amores, novos empregos, novos filhos podem ser percebidos como algo inédito, inesperado, por romper com as crenças limitantes de uma velhice que é vista como incapaz de sentir, de progredir, de fazer acontecer. Além disso, o vestir também aparece nessa imprevisibilidade não somente pelo idoso que escolhe o seu vestir, mas pelas reações da sociedade que se habituou a um envelhecer programado, regular e esperado.

Novamente menciono as cores como possibilidade do imprevisível, bem como a mistura de estampas, tecidos e acessórios. 0 vestir-se nesse regime é pela roupa em si que valoriza e mostra o corpo, mas se sobressai sobre ele. É a roupa que dá visibilidade ao corpo. Como exemplo, cito a designer de interiores e empresária Iris Apfel, de 98 anos de idade, que rompe com a invisibilidade do idoso fazendo uso de acessórios exuberantes, peças de roupas inusitadas e maquiagem bem marcada. Seu visual impressiona e, para alguns, choca. Em recente aula para faculdade da terceira idade, mostrei uma foto da empresária e contei sua história. Percebi sorrisos nos rostos de vários alunos idosos que identificaram no vestir de Iris uma atitude positiva. Mas também escutei comentários críticos de alguns, especialmente mulheres: "Essa aí quer é aparecer", "Ela não reconhece a idade que tem".

Iris Apfel pode ter um querer fazer de manipulação para romper com a insignificância e invisibilidade da velhice, colorindo e destacando essa existência por meio de suas roupas. Cito-a aqui no regime de acidente, especialmente pela percepção do outro, de quem a enxerga por ser uma novidade, um vestir inusitado diante do que sempre foi prescrito para o idoso, associando-o a um dever ser comportado e discreto. Pollini (2014, p. 20) destaca que a "geração baby boomers que está hoje envelhecendo não quer ser vista como os idosos de outros tempos, uma vez que eles realmente viveram uma experiência geracional totalmente distinta”. A autora aponta uma entrevistada, de 73 anos, que aparece no documentário de 2013 Fabulous Fashionistas (lançado pelo canal britânico Chanel 4 e dirigido por Sue Bourne), que confirma o repúdio à imagem tradicional do idoso ao afirmar que usar bege pode matar!

c) Ajustamento: 0 ajustamento ideal entre idosos e sociedade estaria na percepção do envelhecer como experiência original. Beauvoir (2018) destaca que o idoso não é um adulto mutilado, assim como a criança também não é um homem inacabado. Ajustar-se potencialmente às questões pertinentes à idade é uma maneira de experimentar uma bela velhice vigorosa, ou seja, quando o sujeito encontra seu equilíbrio moral e físico. 
Sobre o vestir, o que importa no ajustamento é o fazer sentir, no qual roupa e corpo formam uma justaposição perfeita. É o idoso que se veste para ser ele mesmo, reforçando sua identidade. Não há imposições da roupa sobre o corpo ou vice-versa, sendo a potência do corpo reconstruída no poder da roupa em uma união harmoniosa.

Se as funções do vestir estão associadas à proteção, modéstia, adorno e diferenciação, outro elemento pode ser incluído. 0 vestir pode também representar, na velhice, uma escapatória, uma forma de poetizar a vida por meio de novos arranjos e escolhas que combinem com o modo de viver e com a identidade do idoso. Contrapondo a crônica de Luiz Fernando Veríssimo, referencio o texto da humorista e escritora norte-americana Erma Bombeck. Erma descreve de forma divertida como a mulher se vê no espelho, dos três aos 80 anos. As transformações vão desde a menina cheia de sonhos, de um querer ser princesa, passando pela fase da mulher que se percebe cheia de autocríticas e autoimagem negativa até chegar aos 80, quando simplesmente não se incomoda mais em se olhar no espelho, coloca um chapéu violeta e vai se divertir com o mundo. É um fazer sentir no qual há a libertação de um parecer para um ser!

O chapéu violeta simboliza essa liberdade, assim como o blazer vermelho usado quando se comemora a entrada na velhice. Beauvoir (2018) atribui essa liberação como uma das grandes vantagens da maturidade, estando os idosos em uma posição privilegiada por não serem mais definidos pelas suas funções sociais, o que os autorizaria a decidirem sobre seus comportamentos, não de acordo com determinadas regras, mas segundo seus próprios gostos. Essa liberdade pode ser percebida no vestir do idoso que opta por roupas que permitam uma nova experiência estésica visual e tátil como desenrolar figurativo, temático e narrativo, permitindo-lhe outras possibilidades de sentir as relações do corpo com as roupas. $\mathrm{O}$ jogo de contrastes das cores das roupas no corpo, a materialidade do tecido que ganha corporeidade e volume, as possibilidades de tecidos fluidos e flexíveis apontam para um rompimento da invisibilidade do idoso que deseja ser sujeito de si na sociedade, demandando participação nas atividades econômicas, sociais e de lazer. A liberdade na movimentação dos corpos com o uso das roupas também é um aspecto importante a ser considerado. Ela está não só nos movimentos das roupas, mas na própria essência do envelhecer, na qual o idoso busca autonomia e disponibilidade para se preocupar mais consigo mesmo.

Esse desenrolar é circunstancial, ou seja, em cada situação o idoso como destinador de si escolhe suas roupas em uma sintaxe própria. Haverá momentos que porta-se de forma prática e funcional e, em outros, que poderá ser um destinador estético que deseja ser contemplado. 0 que prevalece é a sua liberdade e a possibilidade de usar o ato de se vestir como escapatória e poetização da vida.

A nova experiência estésica visual pode ser percebida em Fabulous Fashionistas que é estrelado por mulheres com idade média de 80 anos que destaca um ponto comum nas entrevistas sobre os diversos estilos de se vestirem: todas têm grande satisfação no ato de vestir e não usam a moda com o objetivo de parecerem mais jovens, mas por desejarem um visual bonito. Essa mudança de visibilidade também é mostrada por meio da proliferação dos diversos blogs de estilo com fotografias de pessoas acima dos 60 anos. 
Dessa forma, a terceira idade pode ser um momento privilegiado para o exercício da criatividade e da autonomia, desde que não caia novamente em um dever ser, em um padrão de comportamento estético. Tal ideal conceberia, além de modelos de juventude, protótipos de terceira idade enquadrados esteticamente, o que empobreceria possibilidades e experiências variadas do exercício criativo que as roupas podem oferecer. As roupas e a moda sempre foram elementos privilegiados no processo de elaboração da individualidade e da sociabilidade.

O exercício da moda torna-se um elemento valioso riquíssimo quando aberto ao processo de reinvenção de identidade e quando é peça integrante da celebração da vida, e isso só se dá quando a moda está aberta à diversidade e recusa a padronização. Essa liberdade dos papéis prescritivos permite ao idoso a invenção dos próprios códigos e condutas, sendo o momento da velhice propício para as realizações que não foram empreendidas em períodos anteriores da vida. (POLLINI, 2014, p. 20)

Para ilustrar e resumir as possibilidades do vestir na velhice descritas anteriormente, apresento figura baseada no modelo de regimes de interação proposto por Landowski.

FIGURA 1 - OS SENTIDOS DA MODA NA MATURIDADE

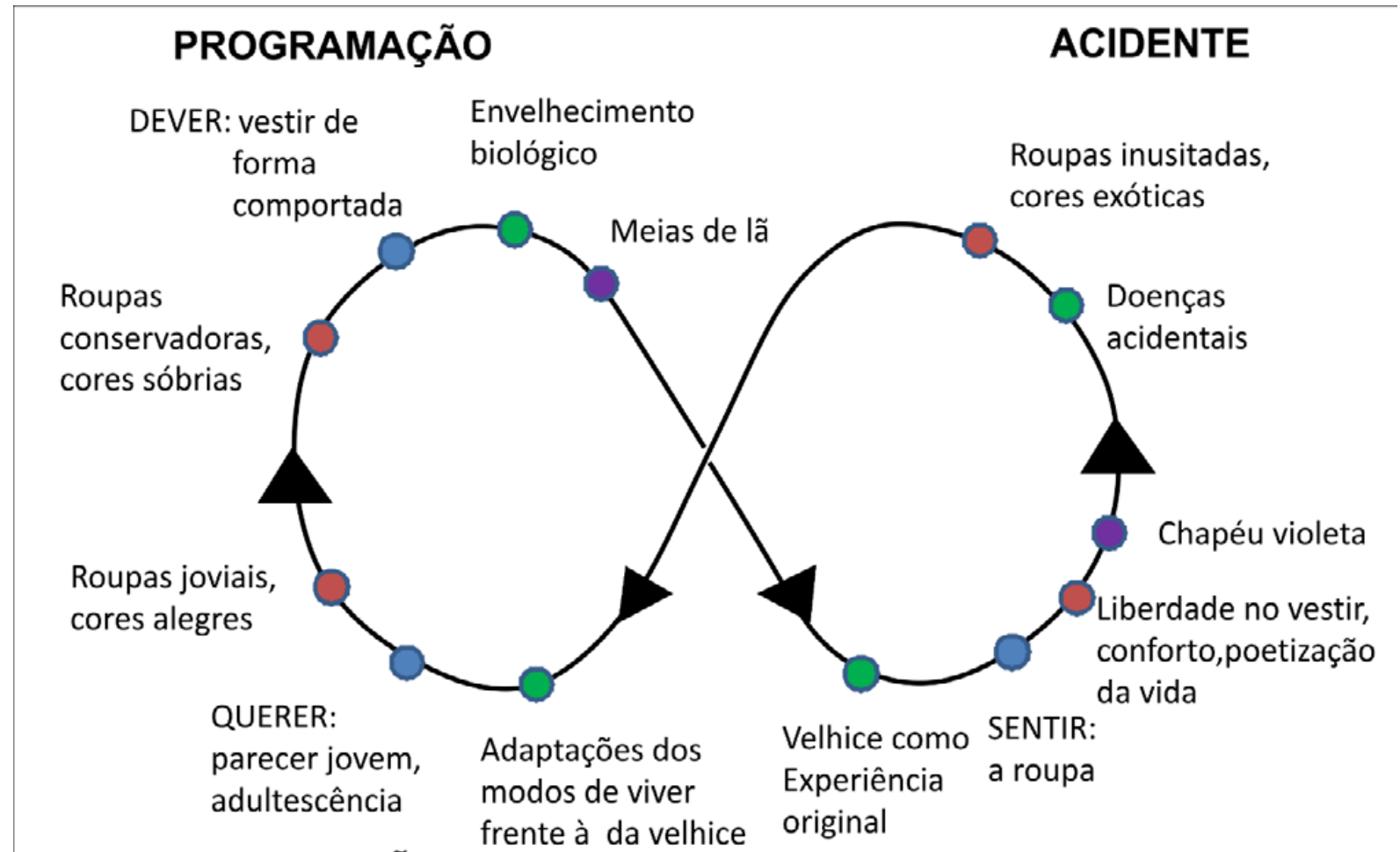

MANIPULAÇÃO

AJUSTAMENTO

FONTE: Elaborada pela autora baseada no esquema proposto por LANDOWSKI, Eric. Sociossemiótica: uma teoria geral do sentido. Galáxia (São Paulo, on-line), n. 27, jun. 2014, p. 15. 
As descrições acima a partir dos regimes de interação são uma das diversas possibilidades de compreensão dos sentidos entre o corpo e a roupa do idoso. Destaco ainda que o caráter dinâmico e fluido desses diálogos permite que os idosos transitem entre os quatro sistemas, que poderá variar de acordo com uma situação, com o interactante e com o estilo de vida adotado, entre outros fatores. Assim, o mesmo idoso poderá vestir-se de forma programada para ir à igreja, intencionalmente manipuladora ao sair com os amigos e vestir-se de maneira livre e espontânea em uma festa, por exemplo. De forma acidental e aleatória, o seu vestir também poderá surpreender um filho ou um amigo de infância. Os sentidos serão dados pela experiência em cada momento.

\section{Conclusão}

As variações na escolha do vestuário constituem indicadores importantes dos modos de presença dos idosos, revelando suas formas de viver, suas identidades e até a experiência existencial da relação com o próprio envelhecer. Corpo e roupa se encontram em uma relação plástica e dinâmica, comunicando uma prescrição de um vestir-se esperado, um querer parecer de outra fase, uma experiência estética ou ainda um sentir livre de todas as sensações do vestir.

$\mathrm{O}$ viver rotineiro nos anestesia para os belos significados de uma vida bem vivida. À medida que amadurecemos, nossos ritmos pulsantes são diminuídos, seja pelas condições físicas, seja por uma mudança de valor sentida a partir de uma longa caminhada experimentada. A diminuição desses ritmos traz reflexões importantes sobre os arranjos que escolhemos. Conhecendo melhor as condições do existir, desfrutamos dos significados de pequenos detalhes. 0 envelhecer oferece essa possibilidade de tornar o indivíduo destinador de suas vontades. 0 vestir na velhice, compreendido a partir da construção de novos sentidos com o mundo no tempo presente, pode propiciar novos arranjos dos modos de ser e de estar. Por meio da moda, o sujeito escapa da invisibilidade e adquire um gosto doce do viver na própria medida em que cotidianamente é convidado a viver uma outra vida. A moda exalta o presente e rompe o cotidiano reinaugurando possibilidades de sensibilidade estética por todo e qualquer sujeito vivente.

A relação do indivíduo maduro com a moda, com os tecidos, com as cores e com as suas aparências reflete simulacros de um novo idoso que vem surgindo. Percebe-se que há uma transformação da moda de prescritiva das formas do vestir para uma moda que permite a experimentação do sentir de um corpo que se funde harmoniosamente com as roupas que o vestem.

Entretanto, percebe-se que o mercado da moda e a sociedade em geral ainda não caminham na mesma direção, desencontrando-se do sujeito maduro, destinador de si. 0 mercado ainda nutre um encantamento pelos consumidores mais jovens, mantendo certa distância do idoso, que é invisível para tantos segmentos de produtos e serviços. Compreender a velhice como o tempo e o acontecimento do ser promovendo a arte de envelhecer, de permanecer, como um coroamento da existência é uma necessidade libertadora que beneficiará todas as idades! 


\section{Referências}

BEAUVOIR, Simone de. A velhice. Trad. Maria Helena Franco Martins. 2. ed. Rio de Janeiro: Nova Fronteira, 2018.

BOMBERCK, Erma. Poema disponível no site: https://www.50emais.com.br/o-chapeuvioleta/. Acesso em: 15 jun. 2020.

CARADEC, Vincent. Sexagenários e octogenários diante do envelhecimento do corpo. In: GOLDENBERG, M. Corpo, envelhecimento e felicidade. Rio de Janeiro: Civilização Brasileira, 2011. p. 21-44.

CASTILHO, Kathia. Moda e linguagem. 2. ed. São Paulo: Ed. Anhembi Morumbi, 2004.

DEBERT, Guita Grin. Pressupostos da reflexão antropológica sobre a velhice. In: DEBERT, Guita Grin. Antropologia e velhice. 2 ed. Campinas: IFCG/UNICAMP, no13, 1998. p.7-27

DEMURU, Paolo. De Greimas a Eric Landowski. A experiência do sentido, o sentido da experiência: semiótica, interação e processos sócio-comunicacionais. Galáxia. Revista do Programa de Pós-Graduação em Comunicação e Semiótica. ISSN 1982-2553, [S.l.], dez. 2019. ISSN 1982-2553. Disponível em: <https://revistas.pucsp.br/galaxia/article/view/45630>. Acesso em: 30 jul. 2020.

ESTATUTO DO IDOSO: 2003. Lei n. 10.741, de 1ํ de outubro de 2003. Dispõe sobre o estatuto do idoso e das outras providências. Brasília: Senado Federal.

GOLDENBERG, Miriam. o corpo como capital. Estudos sobre gênero, sexualidade e moda na cultura brasileira. São Paulo: Estação das Letras e Cores, 2010.

GREIMAS, Algirdas Julius. Da imperfeição. 2 ed. São Paulo: Estação das Letras e Cores: CPS, 2017.

IBGE: Projeção da População das Unidades da Federação por sexo e idade: 2000-2030. Disponível em: https://www.ibge.gov.br/estatisticas/sociais/populacao/9109-projecaoda-populacao.html?edicao=21830\&t=resultados. Acesso em: 17 nov. 2019.

LANDOWSKI, Eric. Interações arriscadas. Trad. Luiza Helen Oliveira da Silva. São Paulo: Estação das Letras e Cores: Centro de Pesquisas Sociossemióticas, 2014a.

LANDOWSKI, Eric. Sociossemiótica: uma teoria geral do sentido. Galáxia (São Paulo on-line), n. 27, jun. 2014b. p. 10-20. Disponível em: https://www.scielo.br/pdf/gal/v14n27/02.pdf. Acesso em: 17 out. 2019. 
LANDOWSKI, Eric. Com Greimas: interações semióticas. São Paulo: CPS e Estação das Letras e Cores, 2017.

LIMA, Fernanda Ramos de Albuquerque. Construção do sentido do feminino na publicidade de marcas de beleza. 2020. 136f. Dissertação (Mestrado em Comunicação e Semiótica) - Programa de Pós-Graduçaão em Comunicação e Semiótica da Pontifícia Universidade Católica de São Paulo, São Paulo, 2020.

MINICHIELLO, Victor; BROWNE, Jan; KENDIG, Hal. Perceptions and consequences of ageism: views o folders people. Ageing and Society, v. 20, 2000. p. 253-278.

MORENO, Rachel. A beleza impossível: mulher, mídia e consumo. São Paulo: Ed. Ágora, 2008.

OLIVEIRA, Ana Cláudia. Corpo e roupa na cultura. Revista dObra[s], v. 3, n. 5, Barueri, fev. 2009. p. 40-43.

OLIVEIRA, Ana Cláudia. Corpo e roupa nos discursos da aparência. Trabalho apresentado ao Grupo de Trabalho Cultura das Mídias. XVI Encontro da Compós. Curitiba: Universidade Tuiuti do Paraná, jun. 2007.

POLLINI, Denise. O envelhecimento e a moda: tecendo reflexões. Revista mais 60. Estudos sobre Envelhecimento. São Paulo: Sesc São Paulo, v. 25, n. 60, jul. 2014.

TÓTORA, Silvana. Velhice: uma estética da existência. São Paulo: EDUC, FAPESP, 2016.

VERÍSSIMO, Luiz Fernando. Informe do Planeta Azul e outras histórias. São Paulo: Boa Companhia, 2018. 